\title{
Combined Intravenous Sildenafil and L-Arginine Administration in a Porcine Animal Model: Hemodynamic Safety Profile and Effects on Coronary Blood Flow
}

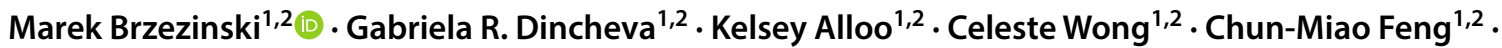 \\ Wynnis L. Tom ${ }^{3} \cdot$ Ali Salahieh ${ }^{1,2} \cdot$ Arthur W. Wallace $^{1,2}$
}

Published online: 27 July 2020

(c) The Author(s) 2020

\begin{abstract}
Background Endothelial dysfunction in the nitric oxide-cyclic guanosine monophosphate pathway is a potential contributor to perioperative myocardial ischemia. The nitric oxide precursor, L-arginine, and the cyclic guanosine monophosphate degradation blocker, sildenafil, have vasodilatory effects under high dosage.

Objective This study examined the hemodynamic safety and effect profiles of the combined administration of L-arginine and sildenafil using an in-vivo pig model.

Methods Hemodynamic safety including mean arterial pressure, central venous pressure, heart rate, coronary vascular resistance, and systemic vascular resistance, as well as effect profiles including cardiac output and left anterior descending blood flow were measured in ten female swine after administrations of L-arginine, sildenafil, as well as combined L-arginine and sildenafil. Measurements were compared using repeated-measures analysis of variance and linear mixed models.

Results The combination of L-arginine and sildenafil produced a significant dose-dependent increase in left anterior descending flow and cardiac output. In contrast, mean arterial pressure, heart rate, central venous pressure, coronary vascular resistance, and systemic vascular resistance did not show any significant changes. No significant change in serum osmolality was observed after administrations of L-arginine.

Conclusions The combined intravenous administration of sildenafil and L-arginine in a porcine animal model was safe, well tolerated, and had at least additive effects on left anterior descending artery blood flow. Simultaneous application of both drugs might have dose-sparing effects leading to desired coronary effects at lower and safer sildenafil and L-arginine plasma concentrations. Hyperosmolality was only a minor factor in L-arginine hemodynamic effects.
\end{abstract}

Arthur W. Wallace

art.wallace@va.gov

1 Department of Anesthesia and Perioperative Care, University of California, San Francisco, San Francisco, CA, USA

2 Anesthesia (129), Veterans Administration Medical Center, 4150 Clement St, San Francisco, CA 94121, USA

3 Pediatric and Adolescent Dermatology, Rady Children's Hospital, University of California, San Diego, San Diego, CA, USA

\section{Key Points}

Combined application of sildenafil and L-arginine was found to be safe and well tolerated in a large animal model.

Combined application of sildenafil and L-arginine had at least additive effects on left anterior descending artery blood flow in a large animal model. 


\section{Introduction}

Endothelial cells help control local vascular tone through the formation of nitric oxide (NO), which mediates vascular smooth muscle relaxation [1-3]. In patients with atherosclerotic coronary arteries, basal secretion of NO is lower and NO synthetic activity in response to mediators is disrupted [4-6]. Therefore, impaired endothelium-dependent coronary blood flow (CBF) is a potential contributor to perioperative myocardial ischemia [7].

$\mathrm{L}$-arginine is the biological precursor for $\mathrm{NO}$ formation [2]. L-arginine is converted into NO and L-citrulline by NO synthase (NOS), allowing L-citrulline to be used as a marker for NO production. Nitric oxide stimulates the conversion of guanosine-5'-triphosphate to cyclic guanosine monophosphate in vascular smooth muscle cells resulting in vasodilatation [2]. In clinical trials, L-arginine has been shown to improve vascular function, reduce paradoxical vasospasm [2, 8-10], and vasodilate coronary arteries [11]. Unfortunately, the L-arginine dose required to achieve its reported effects has been high, limiting clinical applications of L-arginine $[8,11]$. Therefore, compounds that may have L-arginine dose-sparing effects by amplifying its vascular effects were studied [12]. The selective inhibitor of phosphodiesterase type 5, sildenafil citrate, elevates cyclic guanosine monophosphate by blocking its degradation and has been found to improve endothelium-mediated relaxation [13], with vasodilatory effects on the pulmonary [14] and coronary vasculature [15]. In an in vitro study using the porcine internal mammary artery, our group demonstrated that sildenafil administered concurrently with L-arginine had synergistic vasodilatory effects [12]. This finding suggests that the combination of direct (sildenafil) and indirect ( $\mathrm{L}$-arginine) activation of the NOcyclic guanosine monophosphate axis may provide clinical benefit of an increased CBF at lower doses of L-arginine.

A safe and prophylactic increase in endotheliumdependent CBF while preventing vasospasm and ischemia may be particularly relevant in individuals undergoing open-heart surgery as they are often in a tenuous hemodynamic status. No previous study has, however, examined in a large animal model reflecting the acute setting of open heart surgery whether concurrent intravenous sildenafil and L-arginine administration is beneficial by increasing coronary artery blood flow [12] or deleterious because of excessive hypotension, as it has been demonstrated for the combination of sildenafil with $\mathrm{NO}$ donors (e.g., nitroglycerin) $[16,17]$. Therefore, the overall aim of this study was to explore whether concurrent sildenafil and L-arginine administration would safely increase NOdependent coronary vascular resistance (CVR) and CBF in a large animal model, justifying interventional trials in patients undergoing myocardial revascularization. We hypothesized that the concurrent intravascular administration of sildenafil will synergistically amplify the effects of L-arginine on CBF and CVR without negative effects on the overall hemodynamic safety. We tested our hypothesis in an in-vivo porcine model, with primary outcomes including CBF, CVR, and the overall hemodynamic safety profile.

\section{Methods}

\subsection{Surgical Preparation}

After the study protocols were submitted to and approved by the Institutional Review Board of the University of California, San Francisco, ten adult domestic female swine (mean weight: $70.5 \pm 2.6 \mathrm{~kg})$ were sedated with ketamine $(25 \mathrm{mg} /$ $\mathrm{kg}$ intramuscularly). Mask induction with isoflurane was followed by intubation with an endotracheal tube (internal diameter of $6.0 \mathrm{~mm}$ and $45 \mathrm{~cm}$ long). The animals were oxygenated with $100 \%$ oxygen (fraction of inspired oxygen of 1.0) and ventilated to maintain a physiologic arterial carbon dioxide tension. Pancuronium $(0.1 \mathrm{mg} / \mathrm{kg})$ was administered to induce paralysis and isoflurane was used to maintain anesthesia. An angiocathether (20 gauge) was placed in an ear vein for intravenous (IV) fluid administration. Prophylactic antibiotics (cefazolin $1 \mathrm{~g}$ intravenously prior to incision) were given. A left thoracotomy (T4-5) was performed under sterile conditions. Transit time flow probes were placed on the ascending aorta (model 28A; Transonic Systems Inc., Ithaca, NY, USA) and the proximal left anterior descending (LAD) coronary artery $(3 \mathrm{~mm}$, model $3 \mathrm{~S}$; Transonic Systems Inc.). The flow probe cables were tunneled to the animal's back. The thoracotomy was closed and air evacuated with a chest tube. Postoperative analgesia was provided with ketorolac ( $30 \mathrm{mg}$, one time after surgery) and multiple intramuscular doses of buprenorphine $(0.3-0.6 \mathrm{mg}$, every $8 \mathrm{~h}$ ).

\subsection{Hemodynamic Measurements}

To minimize the impact of surgical preparation on data collected, the measurements of systemic hemodynamics and CBF were measured via flow probes located in the ascending aorta and LAD at least 2 days after the surgery. After following the same anesthesia and surgical preparation as for a thoracotomy, the animal's neck was opened using a sterile technique, and angiocatheters (16 gauge) were placed in the left and right internal jugular veins for central venous pressure (CVP) monitoring and for drug and fluid infusions. An additional angiocatheter (20 gauge) was placed in the common carotid artery for blood sampling and pressure 
measurement. After the neck was closed, a suprapubic bladder catheter was placed via a sterile technique for urinary drainage. Arterial pressure and CVP were continuously measured with disposable pressure transducers (Transpac ${ }^{\circledR}$ IV; Abbott Critical Care Systems, North Chicago, IL, USA), which were zeroed in accordance with the level of the right heart and calibrated before each set of measurements using a mercury manometer. The cardiac output (CO) and the LAD blood flow were continuously measured with the two Transonics ${ }^{\circledR}$ Transit Time Flow meters (Model 206 with (-R) Pressure Option; Transonic Systems Inc.), which were also calibrated prior to use. The animal's electrocardiogram was monitored (Electronics for Medicine Monitor Model OM). Coronary vascular resistance and systemic vascular resistance (SVR) were calculated using the following formulas:

$\mathrm{CVR}_{\mathrm{LAD}}=80 \times \frac{\text { Diastolic blood pressure }-\mathrm{CVP}}{\text { LAD blood flow }}\left(\right.$ dynes $\left.\cdot \mathrm{s} \cdot \mathrm{cm}^{-5}\right)$

$\mathrm{SVR}=80 \times \frac{\text { Mean arterial pressure }-\mathrm{CVP}}{\mathrm{CO}}\left(\right.$ dynes $\left.\cdot \mathrm{s} \cdot \mathrm{cm}^{-5}\right)$

Coronary vascular resistance was only calculated during diastole secondary to the zero-flow state in the LAD during systole. Because placing a flow probe circumferentially around the left main coronary artery is technically challenging owing to segment length, measurement of CBF was performed at the LAD vascular bed. This served as a surrogate for the entire coronary circulation. Further, CVP was used instead of left ventricular end-diastolic pressure to calculate CVR to avoid placing a piezoelectric or Millar catheter in the left ventricle. Data were recorded at $100 \mathrm{~Hz}$ using WinDaq data acquisition software (Transonics Systems Inc.).

The safety profile of L-arginine and sildenafil was assessed by looking for clinically and/or statistically significant changes in either mean arterial pressure (MAP) or SVR. We were concerned that the combination of the drugs might cause profound vasodilation resulting in hemodynamic instability or vasodilatory shock.

\subsection{Experimental Protocol}

To limit vasodilatory effects of inhalational anesthesia on the arterial vasculature, fentanyl $(2 \mathrm{mg})$ and diazepam $(20 \mathrm{mg}$ ) were administered as a slow IV bolus followed by continuous fentanyl $(50 \mu \mathrm{g} / \mathrm{kg} / \mathrm{h})$ and diazepam $(250 \mu \mathrm{g} /$ $\mathrm{kg} / \mathrm{h}$ ) IV infusions. Isoflurane was discontinued. Pancuronium $(0.05 \mathrm{mg} / \mathrm{kg})$ was administered every $1-2 \mathrm{~h}$ to maintain paralysis. A 30-min period was allotted for the elimination of volatile agents as well as equilibration of fentanyl and diazepam. After baseline measurements of hemodynamic variables, $\mathrm{CO}$, and the LAD blood flow, the animals were administered the study drugs (see Fig. 1 for protocol overview).

\subsubsection{L-Arginine Hydrochloride (SigmaUltra; Sigma Chemical Company, St. Louis, MO, USA)}

Five boluses of $60 \mathrm{~mL}$ of $10 \%$ L-arginine $(6 \mathrm{~g})$ were injected every $5 \mathrm{~min}$, until the animal had received a total of $30 \mathrm{~g}$ of L-arginine ( $300 \mathrm{~mL}$ of $10 \%$ solution). To monitor L-arginine serum concentrations, blood samples were taken at baseline $(0 \mathrm{~min})$ and then at 5-min intervals following each bolus (at 5, 10, 15, 20, and $25 \mathrm{~min}$ ). Thirtyfive minutes after the last bolus, a final blood sample was taken. A total of $2 \mathrm{~h}$ was allowed for elimination of L-arginine.

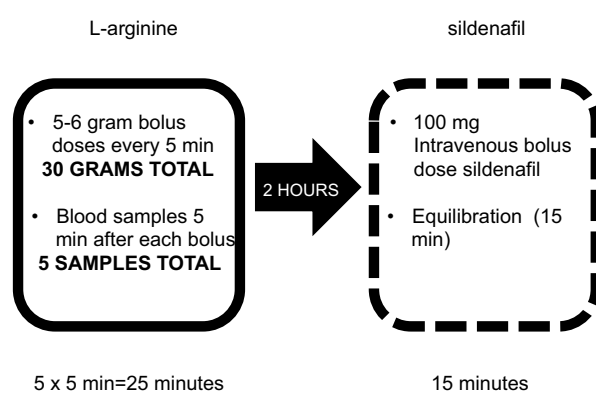

Fig. 1 Flow chart of L-arginine, sildenafil, and mannitol infusion and blood sample collection during the experiment. L-Arginine hydrochloride was injected every $5 \mathrm{~min}$ for five times followed by a 2-h elimination period. Blood samples were taken at baseline $(0 \mathrm{~min})$ and then at 5-min intervals after each bolus (at 5, 10, 15, 20 and $25 \mathrm{~min}$ ) as well as $35 \mathrm{~min}$ after the last bolus. Sildenafil was then administered intravenously for $1 \mathrm{~min}$ and equilibrated for $15 \mathrm{~min}$. After this 15-min equilibration, L-arginine hydrochloride was again injected

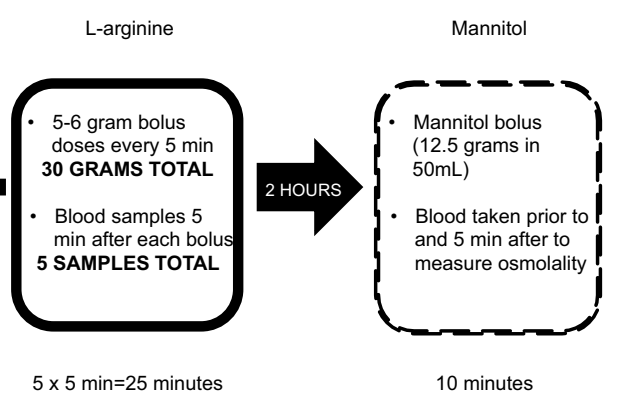

every $5 \mathrm{~min}$ for five times followed by a 2 -h elimination period. Blood samples were taken as described when L-arginine was administered alone. Finally, a bolus of mannitol $(12.5 \mathrm{~g}$ in $50 \mathrm{~mL})$ was administered after $5 \mathrm{~min}$ of baseline data collection to assess the degree of $\mathrm{CO}$ changes in respect to osmolality. A blood sample was taken prior to and $5 \mathrm{~min}$ after the administration of mannitol. Please refer to Sect. 2 for detailed information about doses for each drug 


\subsubsection{Sildenafil Citrate (Viagra ${ }^{\circledR}$; Pfizer Pharmaceuticals, New York, NY, USA)}

A bolus of $100 \mathrm{~mL}$ of $0.1 \%$ sildenafil solution $(100 \mathrm{mg}$ ) was administered intravenously over $1 \mathrm{~min}$, followed by a 15 -min equilibration period. The IV solution of sildenafil was established by grounding one 100-mg tablet with mortar and pestle, dissolving it in $100 \mathrm{~mL}$ of sterile saline, and filtering said solution creating a $1-\mathrm{mg} / \mathrm{mL}$ concentration.

\subsubsection{Sildenafil Plus L-Arginine}

After the 15-min equilibration period of sildenafil citrate, five $60-\mathrm{mL}$ boluses of $10 \% \mathrm{~L}$-arginine $(6 \mathrm{~g})$ were injected intravenously in 5-min intervals, until the animal received a total of $30 \mathrm{~g}$ of L-arginine ( $300 \mathrm{~mL}$ of $10 \%$ solution). To monitor L-arginine serum concentrations, blood samples were taken at baseline $(0 \mathrm{~min})$ and then $5 \mathrm{~min}$ after each bolus (at $5,10,15,20$, and $25 \mathrm{~min}$ ). Thirty-five minutes after the last bolus, a final blood sample was taken. A total of $2 \mathrm{~h}$ was allowed for elimination of L-arginine.

\subsubsection{Mannitol ( $250 \mathrm{mg} / \mathrm{mL}$; Fujisawa USA, Deerfield, IL, USA)}

To assess the degree of $\mathrm{CO}$ changes in respect to osmolality, a bolus of mannitol ( $12.5 \mathrm{~g}$ in $50 \mathrm{~mL}$ ) was administered after 5 min of baseline data collection. A blood sample was taken prior to and $5 \mathrm{~min}$ after the administration of mannitol.

\subsection{Laboratory Analysis}

Blood samples were collected in serum separator tubes and immediately placed on ice. After the tubes were centrifuged for $20 \mathrm{~min}$, the serum was removed and then stored in cryovials at $-80{ }^{\circ} \mathrm{C}$. Serum osmolality was measured using an osmometer (Advanced Instruments; Needleham Heights, MA, USA) by the Veterinary Medical Teaching Hospital Diagnostic Laboratories (Davis, CA, USA). L-Arginine and L-citrulline concentrations were quantified by the Protein Structure Laboratory at the University of California, Davis (Davis, CA, USA) with an ion-exchange chromatographer (Beckman 6300 amino acid analyzer; Beckman Coulter, Fullerton, CA, USA). L-Arginine is converted by NOS into L-citrulline and $\mathrm{NO}$, allowing L-citrulline to be a marker for NO production.

\subsection{Statistical Analysis}

Repeated-measures analysis of variance for multiple comparisons was used to test for differences in plasma concentrations of drugs. Plasma concentrations at each dose were compared to those at the baseline control dose, using
Dunnett's adjustment, and to those at the prior dose level, using Tukey-Kramer adjustment. The linear relationship between plasma concentrations of L-arginine, a biological precursor for NO conversion, and L-citrulline, a marker of NO production, was assessed at each dose using Pearson product-moment correlation coefficient. Finally, a linear mixed model of repeated measures with a compound symmetry covariance model and a random intercept was used to assess differences in the effect at each dose and baseline hemodynamics when L-arginine was administered alone and with sildenafil. Denominator degrees of freedom was calculated via the Kenward-Roger procedure. Residuals were calculated and examined to confirm the assumptions of normal, constant, and independent residuals. All results are reported as sample means (or least-squares means) \pm standard error. A $p$ value $<0.05$ was taken as the significant level for all statistical analyses. All statistical tests were performed with SAS 9.4 (SAS Institute, Cary, NC, USA).

\section{Results}

\subsection{Infusion of L-Arginine Hydrochloride Alone}

\subsubsection{Blood Concentrations of L-Citrulline and L-Arginine}

The average baseline plasma concentration of L-arginine was $160.8 \pm 10.9 \mu \mathrm{M}(n=10$, Table 1$)$. There was a significant increase in the plasma concentration compared with each previous dose of L-arginine for the first three boluses, but not with a further addition of L-arginine (boluses 4 and 5) (Table 1) based on repeated-measures analysis of variance with Tukey-Kramer's adjustment. When compared with the baseline with Dunnett's adjustment, however, plasma concentration of L-arginine was significantly higher after each of the five boluses (12- to 37-fold increases, $p<0.001)$. Thirtyfive minutes after dose 5 , L-arginine plasma concentrations decreased from 5922.1 to $2592.7 \mu \mathrm{M}(p<0.001)$, remaining significantly elevated compared with baseline $(p<0.001)$.

The average baseline plasma concentration of L-citrulline was $53.2 \pm 4.1 \mu \mathrm{M}(n=10$, Table 1$)$. The mean L-citrulline plasma concentration did not show a significant increase following L-arginine administration when compared to baseline or each previous dose based on repeated-measures analysis of variance (Table 1). However, the L-citrulline plasma concentration correlated positively and significantly with $\mathrm{L}$-arginine plasma concentrations at baseline, and at bolus \#1, \#2, \#4, and \#5 (Table 1). L-Citrulline reached the highest mean concentration at dose $4(61.5 \pm 6.7 \mu \mathrm{M})$. Thirtyfive minutes after the last L-arginine bolus, the L-citrulline plasma concentration remained elevated at $60.5 \pm 7.1 \mu \mathrm{M}$, but not significantly different compared with baseline levels $(p=0.2452)$. 
Table 1 Average serum L-arginine and L-citrulline concentrations after each dose of L-arginine and correlation between L-citrulline and L-arginine at each dose

\begin{tabular}{lcll}
\hline $\begin{array}{l}\text { L-Arginine bolus (no } \\
\text { sildenafil) }\end{array}$ & L-Arginine $(\mu \mathrm{M})$ & L-Citrulline $(\mu \mathrm{M})$ & $\begin{array}{l}\text { Correlation between } \\
\text { L-arginine and } \\
\text { L-citrulline }\end{array}$ \\
\hline Baseline & $160.8 \pm 10.9$ & $53.2 \pm 4.1$ & $0.822^{\# \#}$ \\
Bolus \#1 & $1987.0 \pm 116.8^{* * *, \dagger \dagger}$ & $54.7 \pm 5.2$ & $0.817^{\# \#}$ \\
Bolus \#2 & $3139.2 \pm 129.6^{* * *, \dagger \dagger}$ & $53.2 \pm 4.2$ & $0.676^{\#}$ \\
Bolus \#3 & $4143.3 \pm 205.4^{* * *, \dagger \dagger}$ & $54.9 \pm 4.4$ & 0.571 \\
Bolus \#4 & $5232.7 \pm 364.6^{* * *}$ & $61.5 \pm 6.7$ & $0.808^{\# \#}$ \\
Bolus \#5 & $5922.1 \pm 307.4^{* * *}$ & $60.2 \pm 5.9$ & $0.72^{\#}$ \\
30 min post & $2592.7 \pm 268.9^{* * *, \dagger \dagger}$ & $60.5 \pm 7.1$ & 0.622 \\
\hline
\end{tabular}

Data are expressed as sample mean \pm standard error min minutes

*Repeated-measures analysis of variance with Dunnett's adjustment was used to test for changes in concentration relative to baseline levels, ${ }^{*} p \leq 0.05 ; * * p \leq 0.01 ; * * * p \leq 0.001$

${ }^{\dagger}$ Repeated-measures analysis of variance with Tukey-Kramer adjustment was used to test for changes in concentration relative to each previous level, ${ }^{\dagger} p \leq 0.05 ;{ }^{\dagger \dagger} p \leq 0.01 ;{ }^{\dagger \dagger} p \leq 0.001$

\#Pearson correlation was used to test for a linear relationship between L-arginine and L-citrulline at each dose level, ${ }^{\#} \leq 0.05 ;{ }^{\# \#} p \leq 0.01 ;{ }^{\# \#} p \leq 0.001$

\subsubsection{Stable Hemodynamics and Increased Coronary Blood Flow}

The baseline LAD flow was consistent with previously published values [18]. Based on linear mixed models of repeated measures, mean MAP and HR were not significantly changed by the L-arginine administration when compared to the baseline values $(103.4 \pm 5.7 \mathrm{mmHg}$ vs $100.7 \pm 5.5 \mathrm{mmHg}$ and $105.9 \pm 5.7$ beats $/ \mathrm{min}$ vs $106.0 \pm 5.6$ beats $/ \mathrm{min}$, respectively; Table 2 and Fig. 2, $n=10 /$ dose). This was accompanied by significant and dose-dependent increases in LAD flow, $\mathrm{CO}$, and CVP (Fig. 2). After the fifth bolus, LAD flow, CO, and CVP remained significantly higher than their baseline levels $(p<0.001, p<0.001$, and $p=0.004$, respectively, Table 2$)$.
Finally, there was a significant dose-dependent decreases in CVR and SVR (Fig. 2). After the fifth and final bolus, CVR and SVR remained significantly lower than their baseline scores $(p<0.001$ and $p=0.005$, respectively, Table 2$)$.

\subsection{Infusion of Sildenafil Alone}

The hemodynamic effects after the IV administration of $100 \mathrm{mg}$ of sildenafil citrate over time (15 min) were characterized by generalized vasodilatation (decrease in CVR and SVR, $p<0.001$ for both) and a significant reduction in MAP $(p<0.001)$ that persisted during the 15 -min equilibrium after infusion (Fig. 3) based on linear mixed models of repeated measures. There was a significant increase in

Table 2 Hemodynamic effects of L-arginine alone and of L-arginine plus sildenafil

\begin{tabular}{|c|c|c|c|c|c|c|}
\hline \multirow[t]{2}{*}{ Hemodynamic measures } & \multicolumn{3}{|c|}{ L-Arginine alone } & \multicolumn{3}{|c|}{ L-Arginine plus sildenafil } \\
\hline & Pre & End effect & Difference & Pre & End effect & Difference \\
\hline $\mathrm{CO}(\mathrm{L} / \mathrm{min})$ & $7.8 \pm 0.6$ & $8.9 \pm 0.5^{* * *}$ & $1.1 \pm 0.4$ & $9.9 \pm 0.8$ & $11.1 \pm 1.1 * *$ & $1.2 \pm 0.4$ \\
\hline LAD flow (mL/min) & $52.3 \pm 5.3$ & $66.7 \pm 6.6^{* * *}$ & $14.4 \pm 3.6$ & $65.8 \pm 6.1$ & $84.7 \pm 9.5 * * *$ & $18.9 \pm 4.5$ \\
\hline MAP (mmHg) & $100.7 \pm 5.5$ & $103.4 \pm 5.7$ & $2.7 \pm 3.8$ & $87.3 \pm 4.7$ & $96.4 \pm 5.3$ & $9.1 \pm 3.4$ \\
\hline CVP (mmHg) & $10.3 \pm 0.7$ & $11.4 \pm 0.9 * * *$ & $1.1 \pm 0.3$ & $9.5 \pm 0.9$ & $10.0 \pm 1.0$ & $0.6 \pm 0.4$ \\
\hline HR (beats/min) & $106.0 \pm 5.6$ & $105.9 \pm 5.7$ & $-0.1 \pm 4.9$ & $142.4 \pm 9.1$ & $148.7 \pm 8.4$ & $6.3 \pm 8.9$ \\
\hline CVR (dynes $\cdot \mathrm{s} \cdot \mathrm{cm}^{-5}$ ) & $119.2 \pm 6.2$ & $89.1 \pm 4.7 * * *$ & $-30.1 \pm 3.0$ & $77.2 \pm 7.9$ & $70.9 \pm 9.8$ & $-6.3 \pm 5.2$ \\
\hline SVR (dynes $\cdot \mathrm{sec} \cdot \mathrm{cm}^{-5}$ ) & $939.1 \pm 36.1$ & $825.0 \pm 39.3^{* *}$ & $-114.1 \pm 49.6$ & $656.1 \pm 50.2$ & $668.8 \pm 70.3$ & $12.7 \pm 30.6$ \\
\hline
\end{tabular}

Data are expressed as sample mean \pm standard error

The baseline values in L-arginine plus sildenafil were measured after sildenafil was given, but before L-arginine administration

$C O$ cardiac output, $C V P$ central venous pressure, $C V R$ coronary vascular resistance, $H$, heart rate, $L A D$ left anterior descending artery, $M A P$ mean arterial pressure, $S V R$ systemic vascular resistance

*A linear mixed model of repeated measures was used to assess the difference between the value at baseline (pre) and after the last bolus of L-arginine (end effect), ${ }^{*} p \leq 0.05 ; * * p \leq 0.01 ; * * * p \leq 0.001$ 

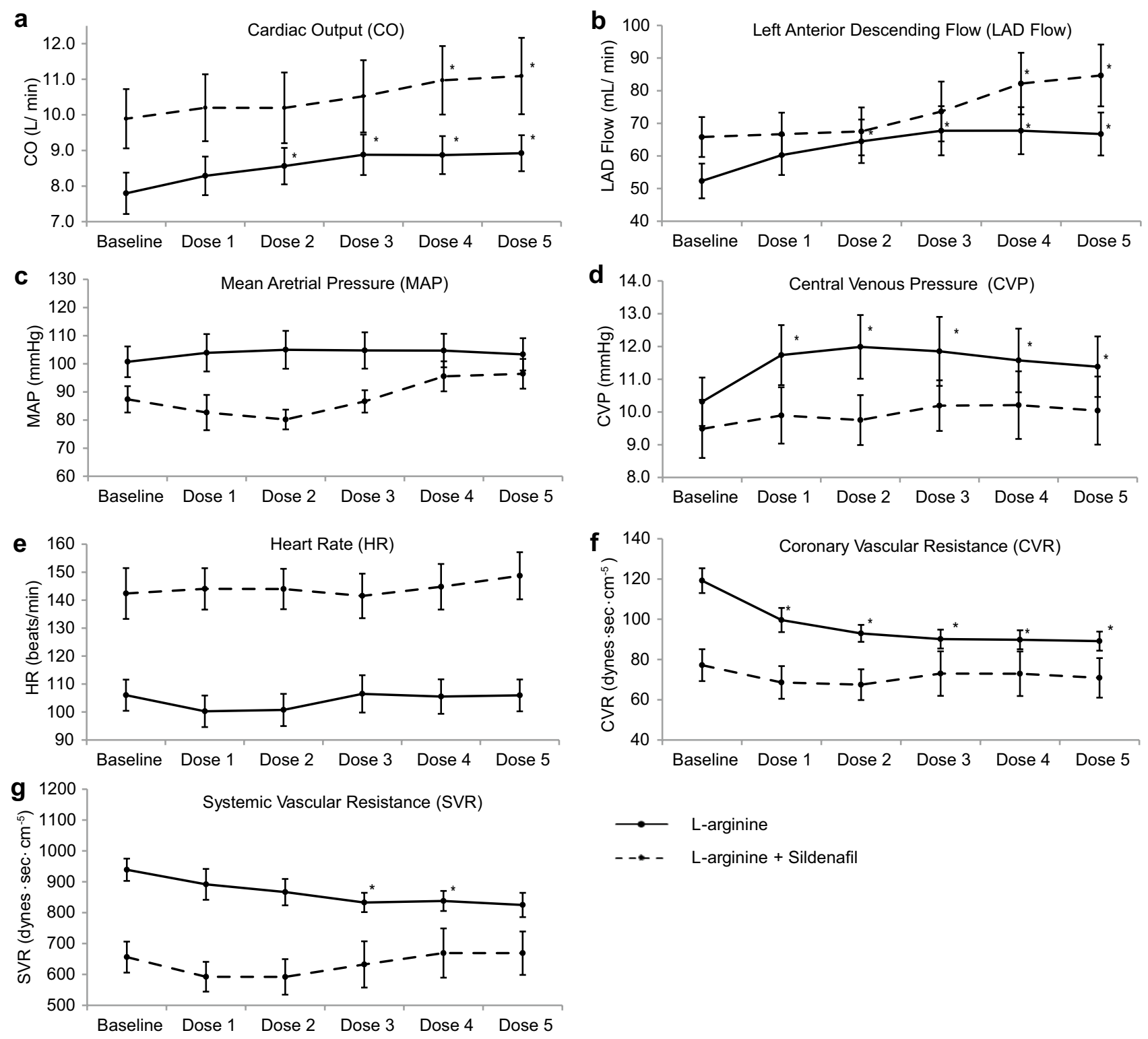

Fig. 2 Mean concentration response curves of hemodynamic safety and effects after L-arginine vs L-arginine plus sildenafil infusions. The mean hemodynamic safety and effects of L-arginine alone (solid lines) and with sildenafil (dashed lines) are compared. a Cardiac output (CO). b Left anterior descending (LAD) flow. c Mean arterial pressure (MAP). d Central venous pressure (CVP). e Heart rate (HR). f

HR during the first 5 min accompanied by a significant increase in LAD artery blood flow and CO compared to their baseline levels. When HR returned to its baseline level, LAD flow and CO decreased rapidly, temporarily undercutting the baseline values. In fact, between the 5th and 12 th minute, there was a significant decrease in LAD artery blood flow followed by a slow return to its baseline (Fig. 3). Central venous pressure showed a significant reduction between the third and ninth minute followed by a slow baseline recovery.

Coronary vascular resistance (CVR). g Systemic vascular resistance (SVR). Data are expressed as sample mean \pm standard error (SE). *Indicates a significant difference of at least $p<0.05$ compared with baseline levels based on the linear mixed models of repeated measures

\subsection{Combined Administration of Sildenafil and L-Arginine}

Based on the linear mixed models of repeated measures that assessed the difference between the values at baseline (measured after sildenafil was given, but before L-arginine administration) and after the last bolus of $\mathrm{L}$-arginine (end effect), MAP, CVP, HR, CVR, and SVR were not significantly affected by the sildenafil and L-arginine administration $(96.4 \pm 5.3 \mathrm{mmHg}$ vs $87.3 \pm 4.7 \mathrm{mmHg}$; 
a

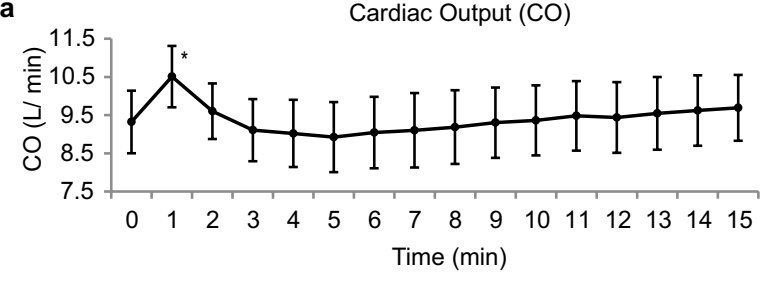

c
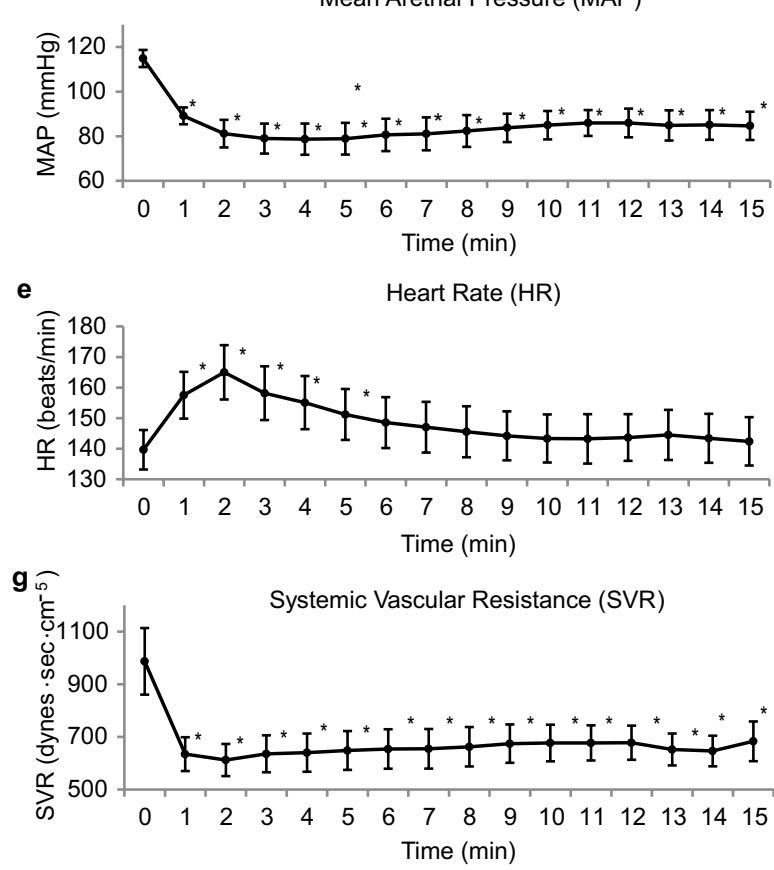

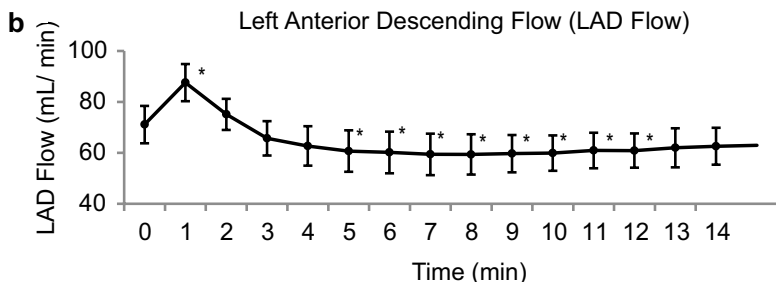

d
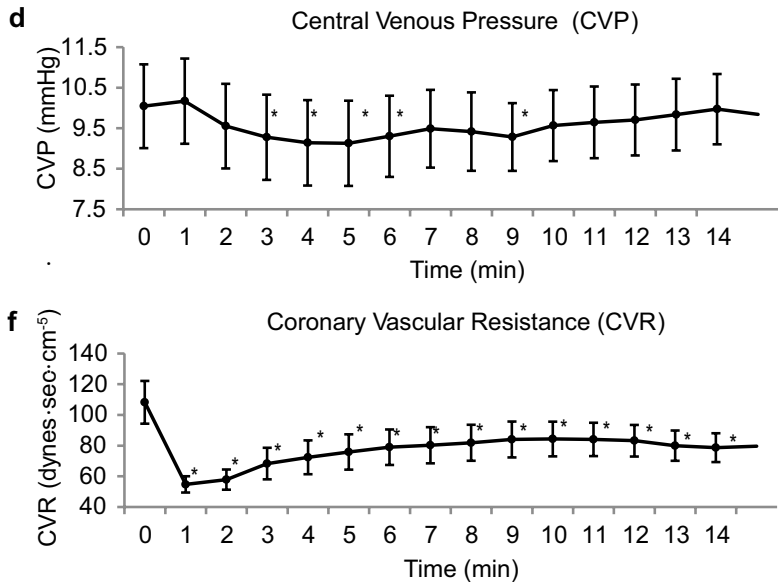

Fig. 3 Hemodynamic safety and effects of sildenafil over time (15 min). The mean trajectory of hemodynamic safety and effects of sildenafil over 15 min was shown. a Cardiac output (CO). b Left anterior descending (LAD) flow. c Mean arterial pressure (MAP). d Central venous pressure (CVP). e Heart rate (HR). f Coronary vascu-

$10.0 \pm 1.0 \mathrm{mmHg}$ vs $9.5 \pm 0.9 \mathrm{mmHg} ; 148.7 \pm 8.4$ beats/ min vs $142.4 \pm 9.1$ beats/min, $70.9 \pm 9.8$ dynes $\cdot \mathrm{s} \cdot \mathrm{cm}^{-5}$ vs $77.2 \pm 7.9$ dynes $\cdot \mathrm{sec} \cdot \mathrm{cm}^{-5}$, and $668.8 \pm 70.3 \mathrm{dynes} \cdot \mathrm{s} \cdot \mathrm{cm}^{-5}$ vs $656.1 \pm 50.2$ dynes $\cdot \mathrm{s} \cdot \mathrm{cm}^{-5}$, respectively; Table $2, n=10$ / dose). In contrast, the end effect of LAD flow and $\mathrm{CO}$ were significantly higher compared with the baseline values $(84.7 \pm 9.5 \mathrm{~mL} / \mathrm{min}$ vs $65.8 \pm 6.1 \mathrm{~mL} / \mathrm{min}, p<0.0001$; $11.1 \pm 1.1 \mathrm{~L} / \mathrm{min}$ vs $9.9 \pm 0.8 \mathrm{~L} / \mathrm{min}, p=0.0057$, respectively, Table $2, n=10 /$ dose).

Comparisons of the LAD flow between L-arginine administration and L-arginine plus sildenafil combined administration demonstrated that each bolus of L-arginine with the presence of sildenafil increased the LAD flow, reaching significance at bolus \#4 $(82.2 \pm 8.1 \mathrm{~mL} / \mathrm{min}, p=0.0087)$ and bolus \#5 (84.7 $\pm 8.1 \mathrm{~mL} / \mathrm{min}, p=0.0012$, Table 3$)$. The magnitude of the combined drug effect was at least additive as both L-arginine and sildenafil are significantly and positively lar resistance (CVR). g Systemic vascular resistance (SVR). Data are expressed as sample mean \pm standard error (SE). *Indicates a significant difference of at least $p<0.05$ compared with the baseline levels based on the linear mixed models of repeated measures

Table 3 Effects of L-arginine alone vs L-arginine plus sildenafil on left anterior descending artery (LAD) flow $(\mathrm{mL} / \mathrm{min})$

\begin{tabular}{lll}
\hline Bolus & L-Arginine alone & L-Arginine plus sildenafil \\
\hline Baseline & $52.3 \pm 6.6$ & $65.8 \pm 8.1^{*}$ \\
Bolus \#1 & $60.3 \pm 6.6$ & $66.7 \pm 8.1$ \\
Bolus \#2 & $64.5 \pm 6.6$ & $67.5 \pm 8.1$ \\
Bolus \#3 & $67.7 \pm 6.6$ & $73.6 \pm 8.1$ \\
Bolus \#4 & $67.7 \pm 6.6$ & $82.2 \pm 8.1^{* *, \dagger \dagger}$ \\
Bolus \#5 & $66.7 \pm 6.6$ & $84.7 \pm 8.1^{* *, \dagger \dagger}$ \\
\hline
\end{tabular}

Data are expressed as least-squares mean \pm standard error

*A linear mixed model of repeated measures was used to assess the difference in LAD flow between L-arginine alone vs L-arginine plus sildenafil, $* p \leq 0.05 ; * * p \leq 0.01 ; * * * p \leq 0.001$

${ }^{\dagger}$ A linear mixed model of repeated measures was used to assess the difference in LAD flow between the final LAD flow in the L-arginine group (after bolus \#5, 66.7 $\pm 6.6 \mathrm{~mL} / \mathrm{min}$ ) vs each bolus in the L-arginine plus sildenafil group, ${ }^{\dagger} p \leq 0.05 ;{ }^{\dagger \dagger} p \leq 0.01 ;{ }^{\dagger \dagger} p \leq 0.001$ 
associated with LAD flow (both $p<0.0001$ for the last dose of L-arginine and sildenafil, respectively).

\subsection{Mannitol}

The change in serum osmolality after $12.5 \mathrm{~g}$ of mannitol $(8.1 \pm 24.3 \mathrm{mOsmol} / \mathrm{kg}$ sample $)$ did not significantly differ from that after $30 \mathrm{~g}$ of L-arginine $(7.7 \pm 25.0 \mathrm{mOsmol} / \mathrm{kg}$ sample). However, L-arginine was associated with a significantly higher LAD artery blood flow when compared with mannitol $(14.4 \pm 0.4 \mathrm{~mL} / \mathrm{min}$ vs $5.5 \pm 0.2 \mathrm{~mL} / \mathrm{min}$, respectively, $p<0.01$, data not shown).

\section{Discussion}

The salient finding of our study is that combined IV administration of sildenafil and $\mathrm{L}$-arginine in a porcine animal model is safe, well tolerated, and has at least additive effects on the LAD artery blood flow and CO (Tables 2, 3; Fig. 2). None of the animals had any adverse hemodynamic changes requiring intervention (Tables 2, 3; Fig. 2). The results appear to support our hypothesis that simultaneous application of both drugs may have dose-sparing effects. This finding is significant as patients undergoing open-heart surgery are often in a tenuous hemodynamic status. Co-administration of L-arginine and sildenafil may allow a safe and prophylactic usage that increases endothelium-dependent $\mathrm{CBF}$ while preventing vasospasm and ischemia.

\subsection{Concurrent Sildenafil and L-Arginine Infusion}

Following our study proving the concept of synergistic vasodilatory effect of sildenafil and L-arginine in an in-vitro porcine internal mammary artery model [12], our group focused on investigating the combination effect in an in-vivo porcine model. No previous study has examined the effects of concurrent IV sildenafil plus L-arginine administration on coronary circulation in a large animal model reflecting the acute setting of open-heart surgery. The current study supports and expands our prior results by demonstrating that L-arginine in the presence of sildenafil induces significant and concentration-dependent increases in LAD artery blood flow (Fig. 2; Table 3), while it is safe and well tolerated (Fig. 2; Table 2). Importantly from a clinical perspective, MAP, CVP, CVR, SVR, and HR remained relatively stable. It is well established that CBF is dependent on multiple factors, including BP, HR, and CVR, for example. The increase in CBF was likely a combination of the small decrease in CVR combined with the small increase in MAP.

The effect of sildenafil alone on LAD flow was comparable to the effect measured after the fifth $\mathrm{L}$-arginine dose administered alone (Table 2). Boluses of L-arginine in the presence of sildenafil increased significantly the blood flow (at bolus \#4 and \#5) showing the additive action of the drugs. This study did not examine the time course of offset of the effects of $\mathrm{L}$-arginine or sildenafil. The decreases in CVR persisted throughout the infusions. We waited $2 \mathrm{~h}$ for them to resolve prior to subsequent tests. A further study would be needed to give the exact time course of offset of the effects.

Synergistic effects of sildenafil and L-arginine have already been described in a rabbit corpus cavernosum [19] and in pulmonary vasculature [14, 20, 21]. Life-threatening pulmonary hypertension in pregnancy was treated successfully with concomitant sildenafil plus L-arginine use [20]. The combination of sildenafil with L-arginine, both at lower doses than when administered alone, may have important clinical applications, as both drugs have side effects [16, 17, $22,23]$. A reduction in the amount of sildenafil and L-arginine doses may therefore lower the risk of adverse events.

For a medication to be clinically useful, the hemodynamic effects must be controllable. This study demonstrated that there were small but statistically significant decreases in SVR with L-arginine that were not large enough to cause clinically significant hemodynamic problems. Combinations of L-arginine and sildenafil did not have statistically significant changes in either MAP or SVR providing a safe hemodynamic profile.

\subsection{L-Arginine Hydrochloride Infusion (Alone)}

Our results support the current view of hemodynamic changes with an IV infusion of L-arginine alone, including peripheral vasodilatation, concentration-dependent decreases in SVR and MAP, an increase in CO, as well as mitigating change in HR [24-27]. Similar to our study, Bode-Boger et al. examined the pharmacokinetic-pharmacodynamic relationship of L-arginine after a single IV infusion of $30 \mathrm{~g}$, and found a significant dose-dependent decrease in blood pressure and total vascular resistance [27].

Our previous work demonstrated that the effects of L-arginine on coronary circulation cannot be predicted from systemic vascular response [11]. Consequently, we used transit time flow meters to quantitatively measure blood flow and resistance of the LAD artery. We found both coronary vasodilatation and an increase in LAD artery blood flow when an IV infusion of L-arginine was administered. Both effects were significant and concentration dependent. The increase in LAD artery blood flow was nearly twice as strong as the changes in CO. This is consistent with our previous findings showing that $\mathrm{L}$-arginine has more selective vasodilatory effects on coronary vasculature than systemic vasculature [11]. Moreover, quantitative human coronary angiography studies demonstrated that both IV and intracoronary L-arginine infusions induce dilatation of coronary arteries 
[28-31]. Finally, L-arginine has been shown to restore the acetylcholine-induced increase in blood flow in patients with impaired endothelium-dependent dilatation of coronary microcirculation, such as in hypocholesteremia [10]. Consistent with the endothelium-dependent NO-mediated mechanism of a vascular tone model, L-NAME, a NO synthesis inhibitor, produced a reduction in LAD artery blood flow in a rat animal model [32]. The effects were then reversed with an IV administration of L-arginine [32]. The stimulation of the L-arginine-NOS-NO pathway is regarded as the dominant mechanism behind the action of L-arginine [31, 33].

L-Arginine is converted by NOS into L-citrulline and NO, making L-citrulline a marker of the production of NO. We measured L-arginine and L-citrulline concentrations from a radial artery sample. The L-citrulline plasma concentration was significantly correlated with the L-arginine plasma concentration at each dose suggesting that L-arginine was converted into L-citrulline while additionally producing NO. However, the L-citrulline plasma concentration did not show a correlation with the L-arginine plasma concentration nor with hemodynamic clinical effects among doses, despite the close temporal pattern between the L-arginine plasma concentration and hemodynamic effects [27, 34, 35]. This discrepancy may be due to the saturation of other L-arginine metabolic pathways, such as L-arginine metabolism by the hepatic urea cycle [34].

\subsection{Mannitol Infusion}

Hypertonic ionic (saline) and nonionic (glucose) solutions have been reported to reduce coronary vascular resistance in direct relation to hyperosmolality [36]. In our study, the administration of $30 \mathrm{~g}$ of L-arginine led to an increase in osmolality similar to the subsequent mannitol infusion. However, the administration of L-arginine was associated with a significantly higher increase in LAD artery blood flow than the mannitol infusion $(14.4 \mathrm{~mL} / \mathrm{min}$ vs $5.5 \mathrm{~mL} /$ $\min , p<0.01)$. The change in $\mathrm{CBF}$ after an L-arginine infusion was 2.6 times the change expected for a similar change in osmolality; this suggests that hyperosmolality is only a minor factor in L-arginine hemodynamic effects [11].

\subsection{Sildenafil Citrate Infusion}

Studies examining the sildenafil effects on systemic, pulmonary, and myocardial hemodynamics used an oral route or slow IV administration [37-43]. Unlike other vasoactive drugs, there is a paucity of data on the hemodynamic effects of a rapid IV bolus administration of sildenafil. In the present study, we administered sildenafil intravenously as a bolus of $100 \mathrm{mg}$ over $1 \mathrm{~min}$. The hemodynamic response $1-2 \mathrm{~min}$ following the injection was characterized by significant arterial vasodilatation (reduced SVR and MAP) and tachycardia, which led to a short yet significant increase in CO. The coronary circulation mirrored this with a significant decrease in CVR while causing a significant increase in LAD artery blood flow despite the markedly decreased MAP. This was followed by rapid normalization of $\mathrm{CO}$, a slow return of $\mathrm{HR}$ back to baseline, and relatively unchanged vasodilatation. There was a decrease in LAD artery blood flow despite a stable MAP. The results appear to support the reported effects of sildenafil, characterized by a vasodilatation-induced reduction in blood pressure [37]. In fact, the peak reduction in blood pressure has been shown to positively correlate with peak sildenafil plasma concentrations [37, 44] followed by a slow return to baseline levels. Phillips et al., using a 100-mg sildenafil oral dose, demonstrated an increase in sympathetic nerve activity selective for a vascular sympathetic drive [43]. The sildenafil oral dose of $100 \mathrm{mg}$ was found to have equivalent peak plasma concentrations when compared to an IV infusion of $40 \mathrm{mg}$ over 40-60 min [37]. In our study, we used a 100-mg sildenafil IV dose infused over $1 \mathrm{~min}$. This higher amount is likely associated with our 2.5 times higher peak plasma concentrations than reported in the study by Phillips et al. [43].

Our findings suggest that even large IV sildenafil doses are well tolerated and not associated with major adverse hemodynamic events. However, our results also suggest that sildenafil administration is associated with tachycardia, possibly owing to the described increase in sympathetic activity [43]. Considering that many patients who may benefit from sildenafil are characterized by ischemic heart disease, a slower administration over a prolonged period should be considered. Jackson et al. described that IV infusion of $40 \mathrm{mg}$ over $60 \mathrm{~min}$ was associated with no adverse events [37].

\subsection{Limitations}

The use of an animal model is an important step in determining the safety profile of the combined use of L-arginine and sildenafil; however, this study has limitations.

There are several limitations to our measurement of $\mathrm{CBF}$ and CVR:

- These measurements were performed only at the LAD vascular distribution; they were surrogates for the whole coronary circulation. This was done because to measure total coronary vascular resistance, one would need to measure total $\mathrm{CBF}$, which would require a flow probe on the left main coronary artery and the right coronary artery. Placing a probe on the left main coronary artery is technically challenging. Thus, the decision was made to measure CVR of the LAD vascular bed.

- We placed a catheter to measure CVP. We did not place a piezoelectric catheter into the left ventricle to measure 
left ventricular diastolic pressure. Typically, CVR would be $\mathrm{CVR}=[$ (aortic diastolic pressure - left ventricular diastolic pressure)/total $\mathrm{CBF}] \times 80$. In a healthy pig, because the ventricular function is not impaired, the CVP provides information on right ventricular end-diastolic pressure, which parallels changes in left ventricular enddiastolic pressure. Central venous pressure was used as a surrogate of left ventricular diastolic pressure to avoid having to place a left ventricular piezoelectric or Millar catheter in the left ventricle.

- Coronary blood flow to the left ventricle occurs during diastole. The pressure gradient between the aorta and left ventricle is zero during systole resulting in zero $\mathrm{CBF}$ in the LAD during systole. Coronary vascular resistance was only calculated during diastole secondary to the zero-flow state in the LAD during systole.

One unexpected finding was the change in heart rate from $106 \pm 5.6$ beats/min to $140 \pm 6.5$ beats/min before sildenafil infusion (Fig. 3e). The elevated heart rate persisted throughout the sildenafil and L-arginine post-sildenafil infusions. Pancuronium, which was given to the animals multiple times throughout the study, is known to increase HR in a dose-dependent manner [45]. Possible dehydration and late effects of L-arginine may also contribute to the increase in HR. Another limitation was that L-arginine lowered SVR in the pigs in this study, but it has had little effect in postbypass patients [11]. One explanation could be that there is already a low SVR in post-bypass patients, thus the addition of L-arginine has minimal effects. Another reason is that the pig vasculature in the current study was not dilated prior to L-arginine infusion. Administration of L-arginine could therefore lead to vasodilatory response and lower SVR. Along the same lines, the difference in the degree of atherosclerosis between patients undergoing open heart revascularization and the large animals used in this study, further limits the translation of the results to humans. Finally, the long-term safety issues were not assessed in this study.

\section{Conclusions}

This study tested the in-vivo response of coronary circulation to concomitant administration of L-arginine and sildenafil in a large animal model. We found that the simultaneous administration of sildenafil and L-arginine was safe and well tolerated in healthy pigs while having additive effects on LAD artery blood flow and CO. The findings support our hypothesis that simultaneous application of both drugs may have dose-sparing effects and additional studies should be performed to optimize desired coronary effects at lower and safer drug plasma concentrations. Co-administration of L-arginine and sildenafil may allow a safe and prophylactic usage that increases endothelium-dependent $\mathrm{CBF}$ while preventing vasospasm and ischemia.

Author Contributions AWW helped design the study, conduct the study, collect the data, analyze the data, and prepare the manuscript as the principal investigator. MB helped analyze the data and prepare the manuscript as the first author. WLT and AS helped conduct the study, collect the data, and prepare the manuscript. GRD, KA, CW, and C-MF helped analyze the data and prepare the manuscript.

\section{Declarations}

Funding This study was supported by the Northern California Institute for Research and Education, San Francisco, CA and VA Merit Review Funding.

Conflict of interest Marek Brzezinski, Gabriela R. Dincheva, Kelsey Alloo, Celeste Wong, Chun-Miao Feng, Wynnis L. Tom, Ali Salahieh, and Arthur W. Wallace have no conflicts of interest that are directly relevant to the content of this study.

Ethics approval An independent review board (Institutional Review Board of the University of California, San Francisco) reviewed and approved the study protocol.

Consent to participate Not applicable.

Consent for publication Not applicable.

Availability of data and material Not applicable.

Code availability Not applicable.

Open Access This article is licensed under a Creative Commons Attribution-NonCommercial 4.0 International License, which permits any non-commercial use, sharing, adaptation, distribution and reproduction in any medium or format, as long as you give appropriate credit to the original author(s) and the source, provide a link to the Creative Commons licence, and indicate if changes were made. The images or other third party material in this article are included in the article's Creative Commons licence, unless indicated otherwise in a credit line to the material. If material is not included in the article's Creative Commons licence and your intended use is not permitted by statutory regulation or exceeds the permitted use, you will need to obtain permission directly from the copyright holder. To view a copy of this licence, visit http://creativecommons.org/licenses/by-nc/4.0/.

\section{References}

1. Vanhoutte PM, Shimokawa H, Feletou M, Tang EH. Endothelial dysfunction and vascular disease: a 30th anniversary update. Acta Physiol (Oxf). 2017;219(1):22-96. https://doi.org/10.1111/ apha.12646.

2. Forstermann U, Sessa WC. Nitric oxide synthases: regulation and function. Eur Heart J. 2012;33(7):829-37, 37a-d. https://doi. org/10.1093/eurheartj/ehr304.

3. Lee J, Bae EH, Ma SK, Kim SW. Altered nitric oxide system in cardiovascular and renal diseases. Chonnam Med J. 2016;52(2):81-90. https://doi.org/10.4068/cmj.2016.52.2.81. 
4. Bossaller C, Yamamoto H, Lichtlen PR, Henry PD. Impaired cholinergic vasodilation in the cholesterol-fed rabbit in vivo. Basic Res Cardiol. 1987;82(4):396-404.

5. Chester AH, O'Neil GS, Moncada S, Tadjkarimi S, Yacoub MH. Low basal and stimulated release of nitric oxide in atherosclerotic epicardial coronary arteries. Lancet. 1990;336(8720):897-900.

6. Golino P, Piscione F, Willerson JT, Cappelli-Bigazzi M, Focaccio A, Villari B, et al. Divergent effects of serotonin on coronaryartery dimensions and blood flow in patients with coronary atherosclerosis and control patients. N Engl J Med. 1991;324(10):6418. https://doi.org/10.1056/NEJM199103073241001.

7. Hasdai D, Gibbons RJ, Holmes DR Jr, Higano ST, Lerman A. Coronary endothelial dysfunction in humans is associated with myocardial perfusion defects. Circulation. 1997;96(10):3390-5.

8. Clarkson P, Adams MR, Powe AJ, Donald AE, McCredie R, Robinson J, et al. Oral L-arginine improves endothelium-dependent dilation in hypercholesterolemic young adults. J Clin Investig. 1996;97(8):1989-94. https://doi.org/10.1172/JCI118632.

9. Creager MA, Gallagher SJ, Girerd XJ, Coleman SM, Dzau VJ, Cooke JP. L-arginine improves endothelium-dependent vasodilation in hypercholesterolemic humans. J Clin Investig. 1992;90(4):1248-53.

10. Drexler H, Zeiher AM, Meinzer K, Just H. Correction of endothelial dysfunction in coronary microcirculation of hypercholesterolaemic patients by L-arginine. Lancet. 1991;338(8782-8783):1546-50.

11. Wallace AW, Ratcliffe MB, Galindez D, Kong JS. L-arginine infusion dilates coronary vasculature in patients undergoing coronary bypass surgery. Anesthesiology. 1999;90(6):1577-86.

12. Wallace AW, Tom WL. Interaction of L-arginine and phosphodiesterase inhibitors in vasodilation of the porcine internal mammary artery. Anesth Analg. 2000;90(4):840-6.

13. Prieto D, Rivera L, Recio P, Rubio JL, Hernandez M, Garcia-Sacristan A. Role of nitric oxide in the relaxation elicited by sildenafil in penile resistance arteries. J Urol. 2006;175(3 Pt 1):1164-70. https ://doi.org/10.1016/S0022-5347(05)00320-4.

14. Michelakis E, Tymchak W, Lien D, Webster L, Hashimoto K, Archer S. Oral sildenafil is an effective and specific pulmonary vasodilator in patients with pulmonary arterial hypertension: comparison with inhaled nitric oxide. Circulation. 2002;105(20):2398-403.

15. Traverse JH, Chen YJ, Du R, Bache RJ. Cyclic nucleotide phosphodiesterase type 5 activity limits blood flow to hypoperfused myocardium during exercise. Circulation. 2000;102(24):2997-3002.

16. Webb DJ, Muirhead GJ, Wulff M, Sutton JA, Levi R, Dinsmore WW. Sildenafil citrate potentiates the hypotensive effects of nitric oxide donor drugs in male patients with stable angina. J Am Coll Cardiol. 2000;36(1):25-31.

17. Cheitlin MD, Hutter AM Jr, Brindis RG, Ganz P, Kaul S, Russell $\mathrm{RO} J$, et al. Use of sildenafil (Viagra) in patients with cardiovascular disease: Technology and Practice Executive Committee. Circulation. 1999;99(1):168-77.

18. Tayama M, Solomon SB, Glantz SA. Effect of lidocaine on left ventricular pressure-volume curves during demand ischemia in pigs. Am J Physiol. 1998;274(6):H2100-9. https://doi.org/10.1152/ajphe art.1998.274.6.H2100.

19. Sharabi FM, Daabees TT, El-Metwally MA, Senbel AM. Comparative effects of sildenafil, phentolamine, yohimbine and L-arginine on the rabbit corpus cavernosum. Fundam Clin Pharmacol. 2004;18(2):187-94.

20. Lacassie HJ, Germain AM, Valdes G, Fernandez MS, Allamand F, Lopez H. Management of Eisenmenger syndrome in pregnancy with sildenafil and L-arginine. Obstet Gynecol. 2004;103(5 Pt 2):111820. https://doi.org/10.1097/01.AOG.0000125148.82698.65.

21. Lepore JJ, Maroo A, Bigatello LM, Dec GW, Zapol WM, Bloch KD, et al. Hemodynamic effects of sildenafil in patients with congestive heart failure and pulmonary hypertension: combined administration with inhaled nitric oxide. Chest. 2005;127(5):1647-53. https://doi. org/10.1378/chest.127.5.1647.

22. Morgan JC, Alhatou M, Oberlies J, Johnston KC. Transient ischemic attack and stroke associated with sildenafil (Viagra) use. Neurology. 2001;57(9):1730-1.

23. Loscalzo J. What we know and don't know about $\mathrm{L}$-arginine and NO. Circulation. 2000;101(18):2126-9.

24. Calver A, Collier J, Vallance P. Dilator actions of arginine in human peripheral vasculature. Clin Sci (Lond). 1991;81(5):695-700.

25. Chen Y, Du R, Traverse JH, Bache RJ. Effect of sildenafil on coronary active and reactive hyperemia. Am J Physiol Heart Circ Physiol. 2000;279(5):H2319-25.

26. Gokce N. L-arginine and hypertension. J Nutr. 2004;134(10 Suppl):2807S-11S (discussion 18S-19S).

27. Bode-Boger SM, Boger RH, Galland A, Tsikas D, Frolich JC. L-arginine-induced vasodilation in healthy humans: pharmacokinetic-pharmacodynamic relationship. Br J Clin Pharmacol. 1998;46(5):489-97.

28. Drexler H, Fischell TA, Pinto FJ, Chenzbraun A, Botas J, Cooke JP, et al. Effect of L-arginine on coronary endothelial function in cardiac transplant recipients: relation to vessel wall morphology. Circulation. 1994;89(4):1615-23.

29. Tousoulis D, Davies G, Tentolouris C, Crake T, Toutouzas P. Coronary stenosis dilatation induced by L-arginine. Lancet. 1997;349(9068):1812-3.

30. Tousoulis D, Davies GJ, Tentolouris C, Crake T, Lefroy DC, Toutouzas P. Effects of inhibition of nitric oxide synthesis in patients with coronary artery disease and stable angina. Eur Heart J. 1997;18(4):608-13.

31. Tentolouris C, Tousoulis D, Goumas G, Stefanadis C, Davies G, Toutouzas P. L-arginine in coronary atherosclerosis. Int J Cardiol. 2000;75(2-3):123-8.

32. Jones LF, Brody MJ. Coronary blood flow in rats is dependent on the release of vascular nitric oxide. J Pharmacol Exp Ther. 1992;260(2):627-31.

33. Goumas G, Tentolouris C, Tousoulis D, Stefanadis C, Toutouzas P. Therapeutic modification of the $\mathrm{L}$-arginine-eNOS pathway in cardiovascular diseases. Atherosclerosis. 2001;154(2):255-67.

34. Mehta S, Stewart DJ, Levy RD. The hypotensive effect of L-arginine is associated with increased expired nitric oxide in humans. Chest. 1996;109(6):1550-5.

35. Mehta SS, Stewart DJ, Levy RD. The fall in mean BP with L-arginine did not correlate with either the peak plasma levels or the change in the plasma levels of L-arginine or L-citrulline. Chest. 1996;109(5):1550-5.

36. Fleetwood G, Bettmann MA, Gordon JL. The effects of radiographic contrast media on myocardial contractility and coronary resistance: osmolality, ionic concentration, and viscosity. Investig Radiol. 1990;25(3):254-60.

37. Jackson G, Benjamin N, Jackson N, Allen MJ. Effects of sildenafil citrate on human hemodynamics. Am J Cardiol. 1999;83(5A):13C-20C.

38. Katz SD, Balidemaj K, Homma S, Wu H, Wang J, Maybaum S. Acute type 5 phosphodiesterase inhibition with sildenafil enhances flow-mediated vasodilation in patients with chronic heart failure. $\mathrm{J}$ Am Coll Cardiol. 2000;36(3):845-51.

39. Halcox JP, Nour KR, Zalos G, Mincemoyer RA, Waclawiw M, Rivera CE, et al. The effect of sildenafil on human vascular function, platelet activation, and myocardial ischemia. J Am Coll Cardiol. 2002;40(7):1232-40.

40. Kimura M, Higashi Y, Hara K, Noma K, Sasaki S, Nakagawa K, et al. PDE5 inhibitor sildenafil citrate augments endothelium-dependent vasodilation in smokers. Hypertension. 2003;41(5):1106-10.

41. Ishikura F, Beppu S, Hamada T, Khandheria BK, Seward JB, Nehra A. Effects of sildenafil citrate (Viagra) combined with nitrate on the heart. Circulation. 2000;102(20):2516-21. 
42. Herrmann HC, Chang G, Klugherz BD, Mahoney PD. Hemodynamic effects of sildenafil in men with severe coronary artery disease. N Engl J Med. 2000;342(22):1622-6.

43. Phillips BG, Kato M, Pesek CA, Winnicki M, Narkiewicz K, Davison D, et al. Sympathetic activation by sildenafil. Circulation. 2000;102(25):3068-73.
44. Webb DJ, Boolell M, Muirhead G. Cardiovascular effects of phosphodiesterase type 5 inhibition with concomitant nitrate therapy [abstract]. Circulation. 1998;98(Suppl. 17):I-637.

45. Miller RD, Eger EI 2nd, Stevens WC, Gibbons R. Pancuroniuminduced tachycardia in relation to alveolar halothane, dose of pancuronium, and prior atropine. Anesthesiology. 1975;42(3):352-5. 